\title{
O Perfil do Professor e a Política de Formação Continuada dos Docentes da Unipampa
}

\author{
Valmor Rhoden ${ }^{1}$ \\ Juliana Lima Moreira Rhoden²
}

\begin{abstract}
Resumo
Este artigo objetiva identificar o perfil do professor do Ensino Superior brasileiro e das propostas de formação oferecidas no contexto universitário. 0 foco de estudo é a formação inicial e continuada dos professores do Ensino Superior da Universidade Federal do Pampa e o programa de desenvolvimento profissional desta instituição. A instituição fez parte do programa de expansão das universidades federais no Brasil (Reuni), tem uma estrutura multicampi e suas unidades universitárias estão distribuídas em dez cidades localizadas na região do Pampa e Fronteira do Estado do Rio Grande do Sul. 0 perfil dos professores foi construído em consulta ao currículo Lattes de 707 docentes (base de corpo docente de 2015) e a proposta de formação continuada para estes professores foi conhecida por meio dos documentos disponibilizados no site da instituição, referentes à política proposta de formação e desenvolvimento profissional do professor. Tratou-se de um estudo exploratório e descritivo que teve os dados sistematizados numa dimensão quantiqualitativa. A partir dos dados levantados e analisados foi possível identificar alguns aspectos referentes ao perfil dos professores da Unipampa e compreender como foi se configurando a política de formação continuada.
\end{abstract}

Palavras-chave: Docência no Ensino Superior. Perfil docente. Formação continuada. Política de formação.

1 Pós-doutorando em Educação pela UFSM. Professor-adjunto do curso de Relações Públicas da Universidade Federal do Pampa - Campus São Borja. vrhoden6@gmail.com

2 Doutoranda em Educação - Universidade Federal de Santa Maria e professora da Universidade Federal do Pampa, campus São Borja, no curso de Ciências Humanas - Licenciatura. juli.rhoden@ gmail.com 


\section{TEACHER PROFILE AND THE CONTINUED TRAINING POLICY OF UNIPAMPA'S TEACHERS}

\section{Abstract}

This article aims to identify the profile of the Brazilian Higher Education teacher and the training proposals offered in the university context. The focus of this study is the initial and continuing training of the Higher Education's professors of the Federal University of Pampa and the professional development program of this institution. The institution was part of the expansion program of Brazilian's federal universities (Reuni), has a multicamp structure and its university units are situate in ten cities located in the pampa region and in the border of Rio Grande do Sul state. The teacher profile were made through curriculum lattes researches of the 707 teachers (teachers of 2015) and the continuous training proposal for these teachers were known through the available documents in the institution's website, concerning the teacher proposed vocational training and development policy. It was an exploratory and descriptive study that had the systematized data in a quanticalitative dimension. Based on the collected and analyzed data, it was possible to identify some aspects related to the profile of the Unipampa's teachers and to understand how the continuing formation.

Keywords: Teaching in Higher Education. Teaching profile. Continuing education. Training policy.

Recebido em: 15/12/2016

Aceito em: 7/8/2017 
O Programa de Apoio a Planos de Reestruturação e Expansão das Universidades Federais (Reuni) possibilitou a expansão de novos campi nas universidades já existentes e espalhadas pelo Brasil e permitiu, em muitos locais, a criação de novas universidades em algumas cidades do interior do país. Trata-se de um programa que surgiu por meio do Decreto $n^{\circ} 6.096$, de 24 de abril de 2007, tendo como uma das metas principais o aumento nas vagas de ingresso no Ensino Superior, permitindo um acesso democrático e a redução das taxas de evasão em cursos presenciais de Graduação. A proposta, porém, não visou apenas a uma reestruturação de ordem quantitativa, mas também qualitativa. Desse modo é possível destacar que foi uma oportunidade de trazer para as regiões, nas quais se inseriu, o desenvolvimento econômico e social, bem como a oportunidade de estudos universitários a estudantes que residem longe de grandes centros.

Com a expansão das universidades e a criação de novas instituições, surgiram várias demandas para dar conta da ampliação de cursos e vagas às universidades e de melhoria da qualidade da Graduação da educação pública, entre elas a necessidade de contratação de professores para completar o quadro docente de diversas universidades, proporcionando para muitos o ingresso efetivo na carreira docente.

A Universidade Federal do Pampa (Unipampa) está entre as universidades que fez parte desse período de expansão e "é resultado da reivindicação da comunidade da região, que encontrou guarida na política de expansão e renovação das Instituições Federais de Educação Superior, incentivada pelo Governo Federal desde a segunda metade da primeira década de 2000" (UNIVERSIDADE..., 2013, p. 12).

A expansão do Ensino Superior, na metade sul do Rio Grande do Sul, iniciou-se em 2005, por meio de um Acordo de Cooperação Técnica firmado entre o Ministério da Educação (MEC), a Universidade Federal de Santa Maria (UFSM) e a Universidade Federal de Pelotas (UFPel), o qual visou à instalação da nova Universidade Federal do Pampa em dez cidades das regiões da Fronteira Oeste e Campanha do Estado. 
Assim, na época, foi de responsabilidade da UFSM instituir os campi localizados em São Borja, Itaqui, Alegrete, Uruguaiana e São Gabriel e à UFPel competiu a instalação dos campi de Jaguarão, Bagé, Dom Pedrito, Caçapava do Sul e Santana do Livramento. Em setembro de 2006, portanto, as atividades acadêmicas tiveram início nos campi vinculados à UFPel e, em outubro do mesmo ano, nos campi ligados à UFSM. Para dar suporte às atividades acadêmicas, as instituições tutoras realizaram concursos públicos para docentes e técnicos administrativos em educação, além de desenvolverem e iniciarem a execução dos projetos dos prédios de todos os campi. Ainda em 2006 entrou em pauta, no Congresso Nacional, o Projeto de Lei $n^{\circ} 7.204 / 06$, que propunha a criação da Unipampa.

Precisamente em 11 de janeiro de 2008 foi criada efetivamente a Unipampa por meio da Lei $\mathrm{n}^{\circ} 11.640$, e, a partir desse momento passou a ter administração própria. Segundo consta no artigo $2^{\circ}$ desta lei, a Unipampa tem como objetivos ministrar Ensino Superior, desenvolver pesquisa nas diversas áreas do conhecimento e promover a extensão universitária, caracterizando sua inserção regional mediante atuação multicampi na mesorregião Metade Sul do Rio Grande do Sul.

A Unipampa, que tem sua sede situada no município de Bagé, está atualmente consolidada em outras dez outras cidades, cujos campi atuam de forma descentralizada: Alegrete, Bagé, Caçapava do Sul, Dom Pedrito, Itaqui, Jaguarão, Santana do Livramento, São Borja, São Gabriel e Uruguaiana. Segundo consta em seu PDI (2014-2018), essa instituição, mediante a integração entre ensino, pesquisa e extensão, assume a missão de promover a Educação Superior de qualidade, com vistas à formação de sujeitos comprometidos e capacitados a atuarem em prol do desenvolvimento regional, nacional e internacional.

Diante desse cenário, e partindo do pressuposto de que é importante conhecer sobre o perfil dos professores que estão atuando nestas universidades, os quais fizeram parte do processo de expansão da Educação Superior brasileira, procuramos com esta investigação responder aos seguintes questionamentos: Qual é o perfil do professor que atua na Unipampa? Quem são estes docentes? Como a Instituição de Ensino Superior Unipampa, por meio da sua política institucional, oferece a formação continuada aos professores? 
Para o alcance dos objetivos da pesquisa realizamos um estudo exploratório e descritivo. De acordo com Gil (2008), a pesquisa exploratória tem o objetivo de proporcionar uma visão geral, do tipo aproximativo, acerca de determinado fato, principalmente quando o tema é pouco explorado, e as pesquisas descritivas possuem como objetivo a descrição das características de uma população, de um fenômeno ou de uma experiência.

Assim, foram identificados, pela análise realizada nos currículos Lattes, o perfil de 707 professores que integram o corpo docente da Unipampa. Os aspectos analisados para compor o perfil foram: sexo, formação acadêmica, ano de ingresso na Unipampa, tempo de experiência no Ensino Superior, experiência docente anterior à entrada na Unipampa, envolvimento com pesquisa, ensino, extensão e gestão e atuação em outras IES antes da Unipampa. Os dados foram sistematizados numa dimensão quantiqualitativa descritiva, de modo a dar conta de um dos objetivos específicos da pesquisa. Utilizou-se de recursos e de técnicas estatísticas, porém não se abdicou da interpretação dos fenômenos e da atribuição de significados aos dados.

Este estudo também teve o propósito de conhecer a política de formação da Unipampa; para isso, fizemos um levantamento dos documentos disponibilizados no site, a fim de compreender como foi se configurando a política de formação continuada nesta universidade. Sendo assim, esta investigação surge como um movimento necessário de reflexão sobre esta realidade, professores que entraram para atuar em universidades que fizeram parte desse período de expansão do Ensino Superior, neste caso, da Universidade Federal do Pampa. Nesse viés, nossa interlocução inicia-se pelo reconhecimento da importância de problematizarmos estas questões.

\section{Docência Universitária: a complexidade de ser professor no Ensino Superior}

As pesquisas sobre formação de professores e desenvolvimento profissional têm destacado a importância de conhecermos quem são os docentes que atuam no magistério superior. Autores como Anastasiou (2009), Bolzan 
(2008, 2009), Cóssio (2008), Cunha (2009, 2010), Isaia e Bolzan (2006, 2009 , 2010), Isaia, Maciel e Bolzan (2011), Isaia, Bolzan e Maciel, 2009), Morosini (2003), Oliveira e Silva (2012), Pachane (2009), Pimenta e Anastasiou (2002), Pimenta e Almeida (2011), Veiga (2006), Zabalza (2004), entre outros, já vêm nos contemplando com estudos que se referem à docência no Ensino Superior e destacam a importância de investigações que tenham o intuito de aprofundar o tema, ainda carente de estudos empíricos e contextualizados.

Um ponto importante a ser considerado é que ser professor no Ensino Superior envolve vários encargos, relacionados à área de ensino, pesquisa, extensão e gestão institucional. A própria Resolução $\mathrm{n}^{\circ}$ 79, de 28 de agosto de 2014, da Unipampa, deixa claro, no artigo $4^{\circ}$, que são consideradas atividades acadêmicas, próprias do pessoal docente das carreiras de magistério: I. as pertinentes ao ensino, à pesquisa, à extensão, que, indissociáveis, visem à aprendizagem, à produção de conhecimento, à ampliação e à transmissão do saber e da cultura; II. as inerentes ao exercício da gestão institucional, tais como: direção, assessoramento, chefia, coordenação, participação em conselhos, núcleo docente estruturante, comissão e outras atividades, previstas na legislação da própria instituição.

Dessa forma, de acordo com Isaia e Bolzan (2010), "ao refletirmos sobre a tessitura dos processos formativos docentes é fundamental pensarmos que estes processos de construção docente estão imbricados na atividade de aprender a ser professor" (p.5). E que esta aprendizagem docente pode ser concebida como a base central do desenvolvimento profissional, pois o docente aprende a ser professor no Ensino Superior se transformando, se apropriando de saberes e fazeres que são próprios deste nível de ensino.

Conforme Pachane (2009), o professor universitário não se forma hoje para atuar necessariamente numa universidade, mas sim num complexo sistema de Ensino Superior. Assim sendo, torna-se necessário que este professor se prepare permanentemente para agir nesse meio; surgem, então, novas necessidades formativas. 
Segundo Arroyo (2000), a profissão docente se constitui também como uma profissão construída artesanalmente, a partir de práticas concretas, ou seja, tornamo-nos professores no exercício cotidiano da docência. Ser professor ultrapassa os limites da sala de aula e interfere na nossa condição humana, marcando-nos como pessoas e como profissionais.

Vale ressaltar que o trabalho docente é uma categoria complexa, com várias especificidades. Nesse sentido, Pimenta e Anastasiou (2002) observam que o ser professor, no Ensino Superior, não se restringe às atividades realizadas em sala de aula com seus alunos, uma vez que se espera dos docentes seu envolvimento na administração e gestão da universidade, tomando decisões sobre políticas de pesquisa e de financiamento, de ensino e de avaliação, entre outros aspectos que, muitas vezes, não são contemplados num processo de formação profissional.

No Brasil, segundo Pimenta e Almeida (2011), a preparação de docentes para a vida acadêmica, como especialistas em uma área de conhecimento, ocorre normalmente em programas de Pós-Graduação em nível stricto sensu (Mestrado e Doutorado). Nessa formação, a tônica recai, quase sempre, no aprofundamento de conhecimentos e no desenvolvimento de pesquisas em área específica, o que talvez deixe uma lacuna situadano âmbito pedagógico, podendo apresentar-se como uma limitação para o exercício docente.

Como apontam Oliveira e Silva (2012), na própria Lei de Diretrizes e Bases da Educação Nacional - LDB nº 9.394/96 - é apresentada uma concepção de qualificação docente para o Ensino Superior em que os cursos de Pós-Graduação são considerados formadores dos docentes e, conforme referem as autoras, nem sempre os cursos cumprem com o objetivo formativo, pois a pesquisa, apesar de ser parte integrante da qualificação profissional, não pode ser considerada como via única de qualificação.

No mesmo sentido, Anastasiou (2009) comenta:

Embora os profissionais ingressem na docência por concurso, este nem sempre objetiva o domínio dos saberes pedagógicos necessários à docência em sua complexidade, restringindo-se muitas vezes ao domínio da área a ser 
lecionada e à experiência com a pesquisa. Por isso, um dos desafios relativos a esse enfrentamento refere-se à insuficiente formação para a docência exigida no ingresso e vivida pelos profissionais de diversas áreas de formação que atuam como professores, sem ter podido contar com as ferramentas teórico-práticas existentes hoje, em sua formação na Graduação. Constata-se que existem programas de Pós-Graduação que não sistematizam saberes para a docência universitária, e, quando o fazem, essa iniciação se reduz a uma disciplina sobre Metodologia de Ensino Superior, com carga horária média de 60 horas, insuficiente para tal formação, ainda que ressalvemos sua importância [...] (p. 64).

Para a autora, a formação para a profissão docente, por ter saberes próprios, necessita de um processo mais específico e determinado. Destaca, ainda, a importância de se instituírem os grupos de apoio pedagógico e os espaços de formação continuada dos docentes, no sentido da profissionalização para a docência, pois, na maioria das vezes, os professores ingressam na carreira sem estarem preparados para lidar com as demandas impostas pela profissão.

Veiga (2006) chama a atenção para o fato de que formar professores universitários implica compreender a importância do papel da docência, propiciando uma profundidade científico-pedagógica que os capacite a enfrentar questões fundamentais da universidade, como instituição social, uma prática social que reflete as ideias de formação, reflexão e crítica.

É no percurso de sua trajetória que o docente vai construindo o seu saber. Tardif (2011) refere-se aos saberes docentes tendo como eixo central das discussões, primeiramente, a premissa de que a competência docente integra uma pluralidade de saberes; entre esses: os saberes de formação profissional, os saberes disciplinares, os saberes curriculares e os saberes de experiência. Para esse autor, essa pluralidade e heterogeneidade do saber está implicada na atividade docente, portanto o saber profissional dos professores é um amálgama de diferentes saberes, provenientes de fontes diversas, que são edificados, relacionados, mobilizados pelos professores, de acordo com as exigências de sua atividade profissional. Dá destaque, porém, aos saberes da experiência, que são aqueles que resultam do próprio exercício da atividade profissional dos 
professores e são produzidos pelos docentes por meio da vivência de situações específicas relacionadas ao espaço de trabalho e às relações estabelecidas com alunos e colegas de profissão.

De acordo com Pimenta (2012), a mobilização dos saberes dos professores, referidos por ela como saberes da docência é um movimento importante para mediar o processo de construção da identidade profissional dos professores. Desse modo, a autora apresenta três modalidades de saberes docentes que constroem a identidade profissional do professor, os saberes da experiência, os saberes do conhecimento e os saberes pedagógicos.

No que se refere aos saberes da experiência, a autora destaca que os estudantes, quando chegam à formação inicial, já trazem a imagem e estereótipos sobre o que é ser professor, estas marcas e referenciais de alguma maneira influenciam. Assim, como em outro nível, os saberes da experiência também são aqueles que os docentes constroem no seu cotidiano, num processo de permanente reflexão sobre sua prática e em inter-relação.

O conhecimento, como saber docente, para Pimenta (2012), está representado pelos conhecimentos científicos, conhecimentos específicos, contudo a autora enfatiza a distinção entre informação e conhecimento e traz a ideia de conhecimento. "Conhecimento não se reduz à informação. [...] Conhecer implica um segundo estágio: o de trabalhar com as informações classificando-as, analisando-as e contextualizando-as. O terceiro estágio tem a ver com a inteligência, consciência ou sabedoria [...] (PIMENTA, 2012, p. 23).

Já os saberes pedagógicos, para a autora, produzem-se na ação. Ela ressalta que o trabalho desenvolvido pelo professor, em sala de aula, expressa a síntese de um saber pedagógico que é adquirido, em parte, nos cursos de formação profissional e vão sendo construídos e consolidados no cotidiano do seu trabalho. A autora diferencia conhecimento pedagógico e saber pedagógico, a prática docente é, simultaneamente, expressão desse saber pedagógico construído e fonte de seu desenvolvimento.

Corroboramos com o pressuposto de Isaia e Bolzan (2008) de que a aprendizagem de ser professor no Ensino Superior é um longo processo de desenvolvimento profissional e pessoal, além de complexo e marcado por 
diferentes períodos, vivências e experiências. Desse modo, acreditamos que a existência de movimentos que busquem criar dispositivos de formação continuada e em serviço, no campo da universidade, torna-se imprescindível para a qualificação universitária, além de ser espaço para a reflexão sobre a prática e para o aprofundamento dos conhecimentos adquiridos pelo professor no percurso da sua trajetória e para produção de novos saberes.

\section{Perfil dos Docentes da Unipampa}

Com os dados que apresentaremos a seguir procurou-se delinear o perfil dos professores da Unipampa por meio da análise realizada nos currículos Lattes de 707 professores que integram o corpo docente. Os aspectos analisados para compor o perfil foram: sexo, formação acadêmica, ano de ingresso na Unipampa, tempo de experiência no Ensino Superior, experiência docente anterior à entrada na Unipampa, envolvimento com pesquisa, ensino, extensão e gestão, atuação em outras instituições de ensino antes da Unipampa.

Gráfico 1 - Quanto ao sexo

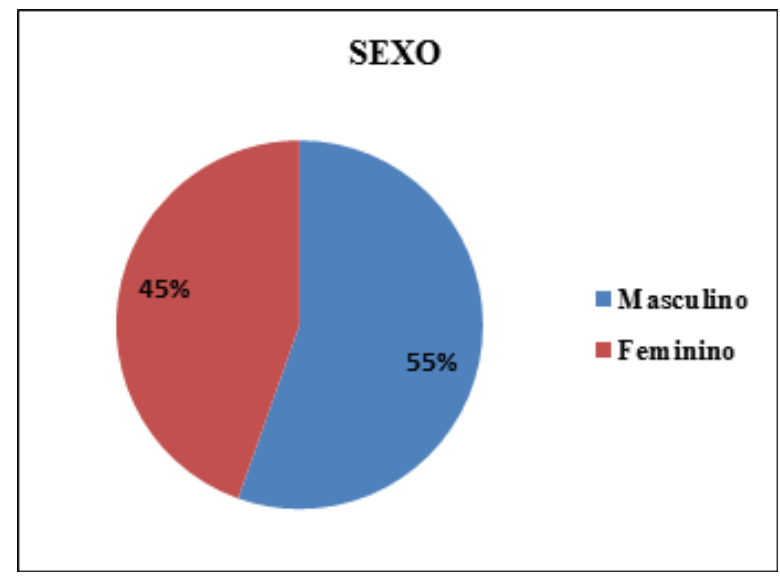

Fonte: Os autores. 
Como podemos verificar no Gráfico 1, dos 707 professores registrados em 2015 e que tiveram os seus currículos analisados, $55 \%$ são do sexo masculino e $45 \%$ do sexo feminino.

\section{Gráfico 2 - Nível de formação}

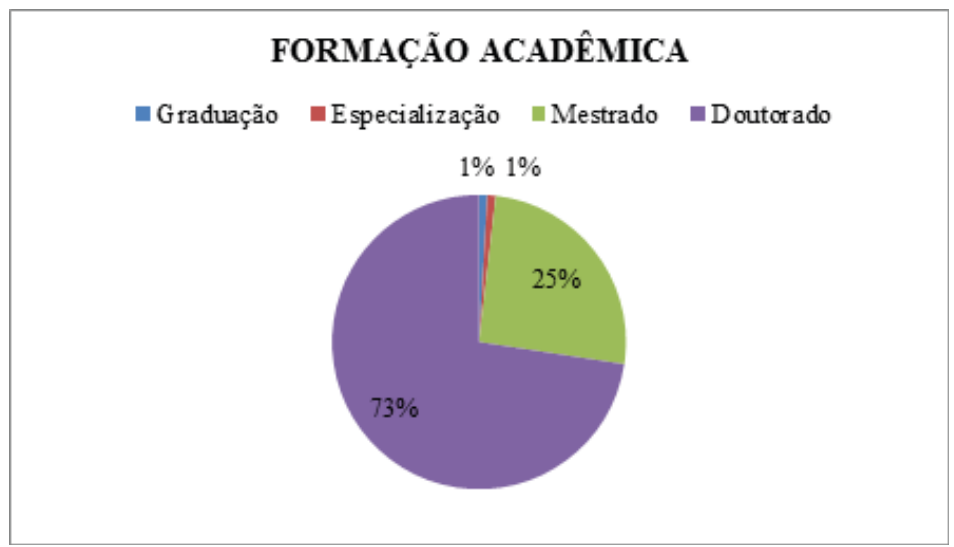

Fonte: Os autores.

Do conjunto de 707 professores, ${ }^{3} 73 \%$, que corresponde a 559 professores, têm Doutorado, sendo que, deste conjunto, 521 deles são professores-adjuntos, somente 1 professor é titular e 37 são associados; $25 \%$, o que corresponde a 197 professores, têm Mestrado, 9 deles são auxiliares e 188 assistentes, 1\% são especialistas, correspondendo a 7 professores, e $1 \%$ são apenas graduados.

Segundo consta no Plano de Desenvolvimento Institucional - PDI (UNIVERSIDADE..., 2013), para ingresso na carreira é necessário título de doutor, conforme Lei $n^{\circ} 12.772 / 2012$, podendo ser concursados servidores com titulação de mestre, especialista ou apenas graduado quando devidamente justificado e aprovado pelo Conselho Superior da Instituição.

3 Número de docentes efetivos em 31/12/2015, dados fornecidos pela Coordenadoria de Gestão de Carreiras - Progepe. Já em dezembro de 2016 este número se ampliou para 841 docentes (639 com Doutorado, 184 com Mestrado, 9 com Especialização e 9 com Graduação). 
No que respeita à progressão do docente, ou seja, à passagem de um nível para o seguinte ocorre após cumprimento do interstício mínimo de 24 (vinte e quatro) meses no último nível da Classe e também depende de uma avaliação de desempenho. O regime de trabalho do professor pode ser de 20h, 40h e $40 \mathrm{~h}$ com dedicação exclusiva (DE). Nesse sentido, os concursos públicos na Unipampa têm sido prioritariamente no regime de 40 horas semanais e dedicação exclusiva (DE).

\section{Gráfico 3 - Ano de ingresso na Unipampa}

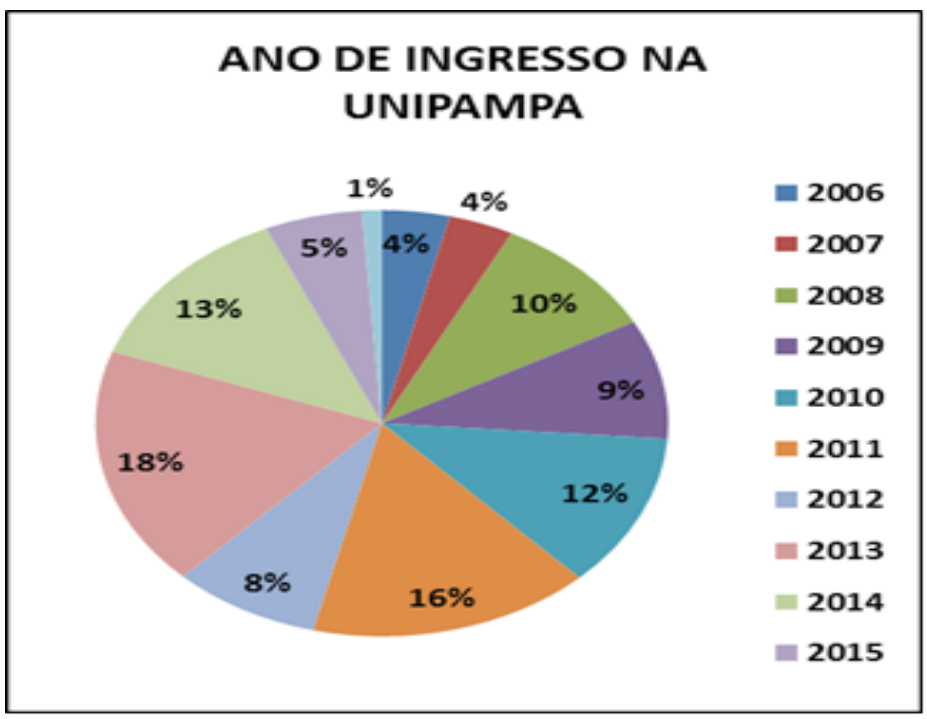

Fonte: Os autores.

Do conjunto dos 707 currículos Lattes analisados, verificamos que $4 \%$ dos docentes ingressaram em 2006, 4\% em 2007, $10 \%$ em 2008, $9 \%$ em 2009,12\% em 2010, 16\% em 2011,8\% em 2012, $18 \%$ em 2013, 13\% em 2014, 5\% em 2015 e apenas $1 \%$ em 2016.

De acordo com Isaia, Maciel e Bolzan (2011), o tempo de experiência na instituição pode ser dividido em três etapas: Inicial (0-5 anos); intermediária (6-15 anos); final 16 anos em diante. Desse modo, se levarmos em conta o tempo 
de experiência na instituição Unipampa, verificamos que 45\% dos professores estão na etapa inicial da carreira como docentes na instituição e 55\% na etapa intermediária.

Para as autoras, a inserção na carreira envolve o enfrentamento de desafios, a partir de uma configuração pessoal/profissional que se torna cada vez mais complexa, à medida que os profissionais tomam consciência de que se trata de uma profissão que tem especificidades que necessitam ser aprendidas.

Para muitos docentes, a entrada efetiva na carreira do magistério superior

[...] ocorre normalmente de forma circunstancial para muitos dos professores, enquanto para um pequeno grupo é uma escolha pessoal, o que indica um forte componente de envolvimento afetivo com a docência desde um período anterior à sua opção profissional. Algumas das percepções marcantes deste período envolvem: a solidão pedagógica, a insegurança, frente aos alunos e à disciplina, tanto em termos de manejo de classe, quanto de domínio de conteúdo da disciplina; a centração no conteúdo específico e na necessidade de vencer o programa a qualquer custo; a inadequação para a docência, ou seja, a falta de domínio de uma pedagogia para este nível de ensino (ISAIA; BOLZAN, 2011, p. 190).

Logo que entram na instituição os professores ainda estão no período de conhecimento dos modelos, das normas, dos valores, das condutas pedagógicas que caracterizam a cultura da instituição Unipampa - campus São Borja.

Nesse sentido, é importante que o professor, ao adentrar na carreira, perceba que está se inserindo no contexto e na vida de uma instituição, ou seja, está envolvido numa relação dialética entre as condições sociais e institucionais. Como destacam Maciel e Isaia (2002, p. 8), "Cada instituição tem uma personalidade própria refletida no comportamento consciente e inconsciente das pessoas que ali convivem". Nessa perspectiva, acaba sofrendo influências da realidade e da cultura da universidade, além da cultura local em que a universidade está inserida, bem como de outras instâncias que se relacionam com a universidade, uma vez que ela também é parte de uma política e de uma cultura que não é só interna. 
Desse modo, nesse processo de aprender a ser professor, devem estar presentes os conhecimentos referentes à instituição, ou seja, a compreensão da presença de uma forma de organização, de uma arquitetura institucional que tem sua cultura, ritos, normas e rotinas que podem estimular ou bloquear possibilidades.

Como lembra Zabalza (2004, p. 79):

\begin{abstract}
Aproximar-se da análise das universidades sob uma perspectiva cultural significa fazer uma aposta em ultrapassar o que constitui sua visão visível e administrativa. Detentoras de uma cultura institucional específica (que as diferencia de outras organizações) e símbolo e reflexo de uma determinada concepção de cultura, as universidades se transformam em um fenômeno social que é, ao mesmo tempo, complexo e dinâmico.
\end{abstract}

Nesse contexto, o professor, como sujeito social, ao adentrar na carreira vai se constituindo docente nas relações que estabelece com a instituição e com os atores que atuam nela. Os relacionamentos que estabelece têm um papel importante para a constituição do ser-professor universitário. Nem todas as instituições têm uma cultura de acolhimento. Isaia (2003, 2007, 2009) cunhou a expressão solidão pedagógica para indicar o sentimento de desamparo que muitos docentes apresentam no início da carreira em decorrência da falta de apoio da instituição e dos próprios colegas, que raramente compartilham conhecimentos pedagógicos e institucionais, importantes para o ato educativo.

Zabalza (2004, p. 117) aponta esta questão como um dilema da identidade profissional dos docentes universitários, ao observar:

Os professores universitários têm uma forte tendência a construir sua identidade e a desenvolver seu trabalho de forma individual, ao ponto de essa ser umas das características principais da universidade, ou seja, algo com que temos de contar, ao menos inicialmente, para qualquer tipo de projeção de crescimento.

Para este autor, a identidade profissional dos docentes costuma dar destaque ao "individual" e estar associada à disciplina que ministra ou à etapa que atende, como se ser um bom professor estivesse somente relacionado ao 
domínio do conteúdo e ao saber transmitir conhecimentos aos alunos, o que corrobora com as colocações de Isaia $(2003,2007,2009)$ sobre a centralização no conteúdo como uma marca dos professores iniciantes e, até mesmo, uma característica presente naqueles que já têm uma certa experiência.

Zabalza ressalta que, diante do individualismo, "mesmo com raras possibilidades de superar a inércia em que se apóia, está a necessidade do exercício profissional mais coeso e institucional" (2004, p. 126), o que implica uma mudança na cultura profissional dos professores.

Desse modo, esta ausência de apoio junta-se ainda à insegurança sentida por estes professores no início da carreira e, também, a uma falta de preparo para atuar no magistério superior. Como argumenta Isaia (2003, 2007, 2009), este é um momento que pode gerar certo sentimento de inadequação à docência, porém a autora entende como uma característica esperada na fase inicial, pois, geralmente, o professor não teve esta preparação anteriormente, ou seja, não teve uma preparação específica para atuar neste nível de ensino, o que vai exigir dele estarem constante aprendizagem.

Gráfico 4 - Envolvimento com pesquisa/extensão/gestão

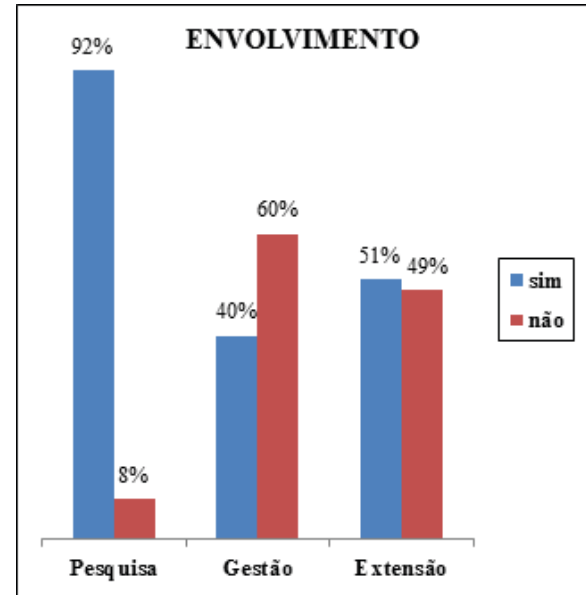

Fonte: Os autores. 
No que diz respeito aos encargos docentes, as atividades de ensino, pesquisa, extensão e gestão institucional estão dispostas na resolução $\mathrm{n}^{\circ} 79$, de 28 de agosto de 2014, aprovada no Conselho Universitário da Unipampa. Tal diretriz tem como objetivo geral normatizar e orientar o planejamento, a execução e o acompanhamento das atividades de ensino, pesquisa, extensão e gestão institucional, exercidas pelos professores da instituição.

As atividades de ensino abrangem as ações dos docentes diretamente vinculadas aos cursos e programas regulares, em todos os níveis e modalidades de ensino, oferecidos pela Unipampa. No que se refere ao ensino, verificamos que, no universo de currículos Lattes analisados, $100 \%$ dos docentes estão inseridos em atividades de ensino, representadas pelas aulas ministradas e por outras ações didáticas. ${ }^{4}$

Vale salientar que, no artigo $9^{\circ}$ da Resolução $n^{\circ} 79 / 2014$ consta que o limite mínimo de carga horária de aulas é de 8 horas semanais, em qualquer regime de trabalho e que o limite máximo de carga horária de aulas não poderá ser superior a $60 \%$, que equivale a 12 horas no regime de 20 horas, e $50 \%$, no regime de 40 horas e de dedicação exclusiva, tudo isso dada a importância da manutenção da qualidade de ensino na instituição e do incentivo às atividades de pesquisa e extensão.

As atividades de pesquisa, ainda segundo a Resolução $n^{\circ} 79$, de 28 de agosto de 2014, são consideradas as ações do professor, preferencialmente em grupos de pesquisa ou individualmente, desde que devidamente registradas. Verificamos que no currículo Lattes de $92 \%$ dos professores consta o envolvimento em atividades de pesquisa, porém no currículo de $8 \%$ não consta a presença dessa atividade.

No que respeita às atividades de extensão, consta na resolução que estas são as ações de caráter comunitário que visam a atender às demandas dos arranjos produtivo, social e cultural em que a Universidade está inserida. Verificamos,

${ }_{4}$ Aulas em cursos de Graduação, Pós-Graduação, supervisão e/ou orientação de estágios, conclusão de curso, tutoria, projetos de ensino, entre outras ações pedagógicas previstas no Projeto Pedagógico de cada curso. 
contudo, por meio da análise do currículo Lattes que, em relação às atividades de extensão, apenas $51 \%$ possuir registrado em seu currículo tal envolvimento, enquanto que no currículo de $49 \%$ não consta o envolvimento com a extensão, o que revela que a atuação do professor ainda é muito mais voltada para o ensino e a pesquisa. A extensão, sua valorização com a centralidade e atenção que lhe são devidas, ainda são um desafio para as universidades.

De acordo com Cunha (2010), os processos de avaliação externa, vigentes para a universidade brasileira, identificam os elementos que estão constituindo os indicadores de sucesso da docência universitária. Os dois componentes que constituem os indicadores são: o componente da investigação e o componente da docência.

O componente da investigação representa a concepção de que o professor é, especialmente, um produtor de conhecimentos e que a universidade, para dar conta do seu perfil acadêmico, precisa estar alicerçada numa forte tradição investigativa. Já o componente da docência deposita nos professores a tradicional tarefa da educação escolarizada, que se expressa pela socialização e distribuição do conhecimento (CUNHA, 2010, p.31).

Assim, também surgiu na universidade a busca pela produção acadêmica, muitas vezes transformada em certo "produtivismo acadêmico." Compreendemos esse movimento como um fenômeno que também é fruto dos processos de avaliação que se caracterizam pela valorização e pelo status relacionado à produção científico-acadêmica, o que, pressupomos, trouxe certa pressão para os professores dentro da universidade.

Já as atividades de gestão institucional são consideradas aquelas inerentes ao exercício de: órgãos colegiados, direção, assessorias, chefia e coordenações previstas no Estatuto. Do universo dos currículos analisados, constatamos que $40 \%$ dos professores já atuaram em algum cargo de gestão na Unipampa, e 60\% ainda não tiveram esta experiência.

5 Valorização mais pela quantidade (materializado muitas vezes pela produção de artigos), mas que não significa que possui qualidade, mas, pelo fato de pontuar, para alguns esta quantidade seria uma demonstração de qualidade. 
Gráfico 5 - Atuação em outras IES antes da Unipampa

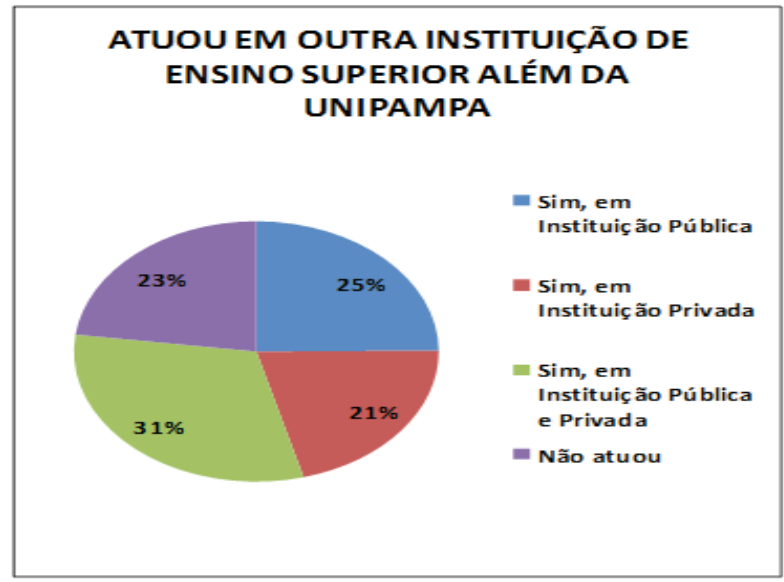

Fonte: os autores.

A grande maioria, ou seja, $77 \%$ dos docentes já foram professores no Ensino Superior, e, deste total, 25\% tiveram sua experiência como professor em instituição pública, muitos atuando como substitutos ou temporários, $31 \%$ tiveram experiência somente em instituições privadas, $21 \%$ experiência em pública e privada e apenas $23 \%$ não tiveram experiência em outra instituição, tendo a Unipampa como sua primeira experiência no Ensino Superior.

De acordo com o PDI (UNIVERSIDADE..., 2013), na Unipampa a experiência profissional é considerada na prova de títulos no momento do concurso público, levando em conta os últimos cinco anos. A profissão docente na Educação Superior exige que o professor esteja disposto a enfrentar questões fundamentais da universidade como instituição social, o que compreende envolver-se com sua própria formação e estar aberto a se desenvolver, independentemente da instituição a que pertence. Principalmente no início do exercício da profissão, todavia, nem sempre os professores encontram-se preparados ou têm apoio para enfrentarem todas as demandas e exigências do trabalho docente.

É importante fazer uma reflexão mais rigorosa da formação do professor universitário. Diferentemente dos outros graus de ensino, esse professor se constituiu historicamente, tendo como base a profissão paralela que exerce ou 
exercia no mundo do trabalho. A idéia de que quem sabe fazer sabe ensinar deu sustentação à lógica do recrutamento dos docentes no ensino superior (CUNHA, 2009, p. 26).

Cabe destacar que, ao nos referirmos à carreira no magistério superior, nos remetemos também aos trabalhos realizados e exigidos do "ser professor" que abrigam processos de formação e desenvolvimento profissional, de saberes e de exigências que são próprias da profissão. Esta carreira, entretanto, envolve uma série de momentos e a ocorrência de transições que refletem necessidades, expectativas, desafios individuais e organizacionais e, no caso da docência, ainda toda uma expectativa da sociedade, que exige do professor estar disposto ao permanente desenvolvimento e à capacidade de assumir atribuições em níveis crescentes de complexidade.

De acordo com Cunha (2010, p.25):

A docência como uma atividade complexa, exige tanto uma preparação cuidadosa como singulares condições para o exercício, o que pode distingui-la de algumas outras profissões. Ou seja, ser professor não é tarefa para neófitos, pois a multiplicidade de saberes e conhecimentos que estão em jogo na sua formação, exigem uma dimensão de totalidade, que se distancia da lógica das especialidades, tão cara a muitas outras profissões [...].

Nessa perspectiva, para dar conta do seu ofício, o professor, ao longo da sua trajetória, precisa articular saberes que compõem a docência universitária, saberes esses que são mobilizados permanentemente em interações diárias e constituídos por meio de aprendizagens e do desenvolvimento profissional.

\section{Política Institucional de Formação Continuada: o desenvolvimento profissional dos professores no âmbito da Unipampa}

Proporcionar um espaço de formação aos docentes por meio de políticas pensadas e organizadas é meta de muitas universidades. Trata-se do que se denomina formação em serviço, um tipo de educação continuada que, segundo Cunha (2010), visa ao desenvolvimento profissional dos sujeitos, no espaço de trabalho, com vistas a aperfeiçoar a qualidade de trabalho. 
Constatamos que a Unipampa, com o intuito da melhora contínua da qualidade de ensino dos cursos de Graduação e Pós-Graduação, desde sua criação, em 2008, já realizou uma série de encontros objetivando incrementar processos contínuos de formação e o desenvolvimento profissional de seus docentes. Lembrando que a docência é um processo em construção que envolve o desenvolvimento profissional, este que é um processo individual e coletivo, "processo contínuo, sistemático, organizado e auto-reflexivo que envolve os percursos trilhados pelos professores, abarcando desde a formação inicial até o exercício continuado da docência" (MARCELO GARCIA, 1999; ZABALZA, 2004).

Segundo os documentos que analisamos, foram realizados eventos que objetivaram a integração, a informação, a reflexão, a formação continuada e em serviço dos professores. Estes docentes, de forma compartilhada, começavam a construir uma universidade e davam os primeiros passos em direção à execução de uma políticainstitucional de formação continuada.

Como consta no PDI (2014-2018, p. 32):

Assim, em março de 2008, foi promovido o primeiro evento de integração e planejamento institucional, intitulado: "Seminário de Desenvolvimento Profissional: Pedagogia Universitária", com a participação de todos os professores da Instituição. Na oportunidade, foram analisados o contexto sociocultural-educacional e político-econômico da região numa nova perspectiva de implantação e inserção da Instituição. A atividade culminante do Seminário foi a elaboração do "perfil do egresso", uma forma de dar sustentação ao projeto de formação acadêmica da Universidade. Esses seminários acontecem anualmente na Instituição e têm como objetivo ser um espaço de formação continuada dos docentes e de (com)partilhamento do que a Universidade tem construído nas práticas docentes, valorizando-as e fomentando a inovação pedagógica, na busca da melhoria da qualidade de ensino e das próprias práticas pedagógicas (UNIVERSIDADE..., 2013). 
Já em 2010 verificamos que se deu a iniciativa da efetiva instituição de uma política para a formação docente, por meio do Programa de Desenvolvimento Profissional Docente. ${ }^{6}$ Trata-se de um Programa sustentado em três pilares: 1) Docência como profissão que se constrói permanentemente e, por isso, tem a necessidade de uma atenção sobre novas práticas e inovações nas áreas do conhecimento; 2) Práticas de formação que tomem a dimensão coletiva, possibilitando a percepção de unidade da Universidade e também da diversidade nas mais diversas formas de atuação do docente; 3) Reflexão sobre a prática, com o uso de experiências dos próprios docentes como forma de gerar debate, reflexão, aprendizado e aperfeiçoamento das suas atividades.

Sua estrutura centra-se nas discussões de perspectivas atuais para a Educação Superior; contexto social atual e desenvolvimento profissional docente, sob o eixo dos processos formativos da pedagogia universitária, constituindo-se em uma política institucional de formação continuada.

O programa constitui-se de três projetos. O Projeto de Acolhida e de Acompanhamento do Professor Ingressante (Paapi), que visa a acolher o novo docente na instituição, apresentando-o a ela, no qual os professores ingressantes participam de seminários e têm a possibilidade de conhecer melhor a Universidade (Projeto Institucional, Regimento, Estatuto, procedimentos administrativos, acadêmicos, pedagógicos; organização estrutural da Universidade, infraestrutura, etc.), sendo orientandos quanto ao trabalho a ser realizado. O Projeto de Aperfeiçoamento à Docência Superior $(\mathrm{Pads})^{7}$ é voltado para os professores que já passaram do momento de ingressantes na instituição, tem como objetivo desenvolver atividades formativas como: seminário de desenvolvimento profissional, oferecido anualmente a todos docentes da universidade, Práticas Pedagógicas na Unipampa: fazendo e acontecendo - painel em que professores apresentam, em forma de exposições e relatos, experiências bem-sucedidas no processo de

${ }^{6}$ Disponível em: <http://goo.gl/aOfcfk>. Acesso em: $1^{\circ}$ jul. 2016.

7 Disponível em: <http://goo.gl/ekuGCh>. Acesso em: 29 jun. 2016. 
ensino e aprendizagem, palestra, oficina, mesa-redonda, minicurso, fóruns por área de conhecimento. O Pads ainda tem como proposta oferecer atividades formativas a distância.

E, ainda, o Projeto de Qualificação da Gestão do Ensino (ProGEn), ${ }^{8}$ executado por meio de ações formativas presencial e a distância(on-line), o qual objetiva qualificar o trabalho do coordenador de curso de Graduação, orientando-o na execução da sua ação na universidade e auxiliando-o para uma gestão de qualidade.

Estão envolvidos neste processo de desenvolvimento profissional e formação continuada dos professores a Coordenadoria de Desenvolvimento Pedagógico (Coordep), que está vinculada à Pró-Reitoria de Graduação - Prograd - os Núcleos de Desenvolvimento Educacional (Nudes), presentes nos dez campi da instituição.

Sabemos que o espaço oferecido pelas universidades promove possibilidades à formação docente, entretanto não garantem a sua concretização. Como ressalta Anastasiou (2009, p.67),

[...] os processos de formação continuada do docente universitário estarão sempre desafiando os grupos de trabalho e os mediadores que neles atuam[...] Para isso os mediadores precisam ter consciência do entorno, da cultura institucional em vigor e de toda a força que esta possui, mas esforçando-se para ir além dela, no sentido de acreditar que novos rumos e processos podem ser traçados e vividos, havendo uma força de transformação e de novas ações se compondo em cada processo vivenciado.

Cunha (2009), ao abordar sobre a docência no Ensino Superior, aponta para a necessidade de assumirmos que a docência é uma atividade complexa, que exige tanto uma preparação cuidadosa, como singulares condições de exercício, o que pode distingui-la de outras profissões. Os espaços de formação precisam

${ }^{8}$ Disponível em: <http://goo.gl/hjN7UP>. Acesso em: $1^{\circ}$ jul. 2016. 
ter clareza da função e da importância que representam na formação de uma pedagogia universitária, constituindo-se num lugar de formação dos professores da Educação Superior.

\section{Apontamentos Finais}

A finalidade deste texto foi trazer alguns dados sobre o perfil dos professores que estão atuando na Unipampa, instituição que fez parte da expansão da Educação Superior brasileira no século XXI, bem como promover algumas reflexões teóricas e como vem ocorrendo o desenvolvimento profissional no âmbito da universidade.

Inferimos que ser professor efetivo no magistério superior público tem algumas tarefas e especificidades que diferem das experiências de outras instituições, nas quais atuaram como docente horista, temporário ou substituto.

Apesar de a maioria dos docentes possuir dedicação exclusiva, uma parcela significativa não expôs em seus currículos projetos e/ou programas de extensão (49\%) e outros $8 \%$ não têm envolvimento em pesquisa.

Percebemos que a Unipampa tem perseguido o objetivo de introdução de uma política para a formação docente. Desde sua criação, tem demonstrado dar atenção aos processos de reflexão sobre a prática e aos estudos de questões pedagógicas entre os docentes em diferentes estágios de formação e experiência profissional, com a finalidade de oferecer um ensino de qualidade.

Ao analisarmos alguns estudos teóricos sobre perfil docente, formação continuada do professor do/no Ensino Superior, espaços formativos e desenvolvimento profissional, verificamos que é carente de estudos empíricos que possam responder algumas questões, e este é um dos propósitos de nossa investigação. A relevância desta pesquisa coloca-se, pois, também na possibilidade de conhecer o perfil docente dentro de um contexto institucional, além dos espaços de formação e as redes de mediações, responsáveis pela construção da professoralidade e da aprendizagem da docência no Ensino Superior.

Não obstante a relevância social do tema, tocar nessa problemática parece-nos uma importante contribuição para o avanço das pesquisas em educação, principalmente no que se refere à formação continuada e em serviço, 
à aprendizagem da docência e ao desenvolvimento profissional do professor no Ensino Superior. Cabe ressaltar que o estudo não se encerra aqui, visto que este irá gerar outros olhares e perspectivas, pois perguntas ainda permanecem e se ampliam.

\section{Referências}

ANASTASIOU, Léa das Graças C. A teoria e a prática de processos de formação continuada do docente universitário. In: PIMENTA, Selma; ALMEIDA, Isabel (Org.). Pedagogia universitária. São Paulo: Ed. da Universidade de São Paulo, 2009.

ARROYO, Miguel Gonzalez. Ofício de mestre: imagens e auto-imagens. Petrópolis: Vozes, 2000.

BOLZAN, Doris P. V. Formação de professores: compartilhando e reconstruindo conhecimentos. 2. ed. Porto Alegre: Mediação, 2009.

Pedagogia universitária e processos formativos: a construção do conhecimento pedagógico compartilhado. In: EGGERT, Edla et al. (Org.). Trajetórias e processos de ensinar: didática e formação de professores. 1. ed. Porto Alegre: Edipucrs, 2008. p. 102-120. V. 1.

CÓSSIO, Maria de Fátima. Políticas institucionais de formação pedagógica e seus efeitos na configuração da docência e na qualidade universitária: um estudo sobre as IES comunitárias do RS. 2008. Tese (Doutorado) - Universidade Federal do Rio Grande do Sul, UFRGS, Porto Alegre, 2008.

CUNHA, Maria Isabel. O lugar da formação do professor universitário: o espaço da pós-graduação em educação em questão. Rev. Diálogo Educ., Curitiba, v. 9, n. 26, p. 81-90, jan./abr. 2009. Disponível em:<http://goo.gl/h2W8k3>. Acesso em: 19 abr. 2015.

. Trajetórias e lugares de formação da docência universitária: da perspectiva individual ao espaço institucional. Araraquara: Junqueira \& Marin Editores, 2010.

GIL, Antonio Carlos. Como elaborar projetos de pesquisa. 5. ed. São Paulo: Atlas, 2008. ISAIA, Silvia M. A. Professor do ensino superior: tramas na tessitura. In: MOROSINI, Marília (Org.). Enciclopédia de pedagogia universitária. Porto Alegre, RS: Fapergs; Ries, 2003. p. 241- 251.

ISAIA, Silvia M. A. Aprendizagem docente como articuladora da formação e do desenvolvimento profissional dos professores da Educação Superior In: Pedagogia universitária e aprendizagem. Porto Alegre: Edipucrs, 2007. p. 153-165. V. 2. 
ISAIA, Silvia M. A. Na tessitura da trajetória pessoal e profissional: a constituição do professor no Ensino Superior. In: ISAIA, Silvia M. A.; BOLZAN, Doris; MACIEL, Adriana M. R. (Org.). Pedagogia universitária: tecendo redes sobre a educação superior. Santa Maria: UFSM, 2009. p. 95-106.

ISAIA, Silvia M. A.; BOLZAN, Doris P. V. Movimentos construtivos da docência/ aprendizagem: tessituras formativas. In: ENCONTRO NACIONAL DE DIDÁTICA E PRÁTICA DE ENSINO, ENDIPE. 15., 2010, Belo Horizonte. Anais... Belo Horizonte: UFMG, 2010. p. 114. V. 1. Disponível em: <https://goo.gl/zCsVHq>. Acesso em: 23 abr. 2015 .

. Tessituras formativas: articulação entre movimentos da docência e da aprendizagem docente. In: ISAIA, S.; BOLZAN, D.P.V.; MACIEL, A.M.R. (Org.). Qualidade da educação superior: a universidade como lugar de formação. Porto Alegre: Ed. da PUCRS, 2011. p. 187-190.

Aprendizagem docente na educação superior: construções e tessituras da professoralidade. Revista Educação, Porto Alegre: PUC-RS, ano XXIX, n. 3 (60), p. 489-501, set./dez. 2006. Disponível em: < http://w3.ufsm.br/gtforma/estagio1/4154c7526f9f2cd 5555e7e0a21267049.pdf>. Acesso em: 12 mar. 2015.

Construção da profissão docente: possibilidades e desafios para a formação. In: ISAIA, Silvia M. A.; BOLZAN, Doris; MACIEL, Adriana M. da R. Pedagogia universitária: tecendo redes sobre a Educação Superior. Santa Maria: Editora da UFSM, 2009. p. 163-176.

Compreendendo os movimentos construtivos da docência superior: construções sobre pedagogia universitária. Linhas Críticas, Brasília, v. 14, n. 26, p. 43-59, jan./jun. 2008.

ISAIA, Silvia M. A.; BOLZAN, Doris; MACIEL, Adriana M. da R. Pedagogia universitária: tecendo redes sobre a Educação Superior. Santa Maria: Ed. da UFSM, 2009.

ISAIA, Silvia M.; MACIEL, Adriana; BOLZAN, Doris. Pedagogia universitária: desafio da entrada na carreira docente. Educação. Revista do Centro de educação UFSM, Santa Maria, vol. 36, n. 3, p. 425-440, set./dez. 2011.

MACIEL, A. M. R.; ISAIA, S. M. A. Trajetórias do professor do ensino superior: para (re)pensar o seu desenvolvimento profissional. In: SEMINÁRIO DE PESQUISA EM EDUCAÇÃO DA REGIÃO SUL, 4. Na contracorrente da universidade operacional. 2002, Florianópolis: Coordenadoria de Comunicação do CED/UFSC, 2002. p. 1-11. V. 1. Disponível em:<http://goo.gl/u33mvk>. Acesso em: 8 out. 2016.

MARCELO GARCIA, Carlos. Formación del profesorado para el cambio educativo. 2. ed. Barcelona: EuB, 1999. 
MOROSINI, M.C. et al. (Org.). Enciclopédia de pedagogia universitária. Porto Alegre: Fapergs; Ries, 2003.

PACHANE, Graziela Giusti. Formação de docentes universitários frente ao um mundo em transformação. In: ISAIA, Silvia M. A.; BOLZAN, Doris; MACIEL, Adriana M.da R. Pedagogia universitária: tecendo redes sobre a Educação Superior. Santa Maria: Ed. UFSM, 2009. p. 249-266.

OLIVEIRA, V.S.; SILVA, R.F. Ser bacharel e professor: dilemas na formação de docentes para a educação profissional e Ensino Superior. Holos, Rio Grande do Norte, ano 28, vol. 2, 2 maio 2012. Disponível em: <http://goo.gl/Deh2ju>. Acesso em: 4 maio 2015. PERRENOUD, P. A prática reflexiva do oficio de professor: profissionalização e razão pedagógica. Porto Alegre: Artmed, 2002.

PIMENTA, S. G. (org.). Saberes pedagógicos e atividade docente. 8. ed. São Paulo: Cortez, 2012.

PIMENTA, S. G.; ANASTASIOU, L. Docência no Ensino Superior. São Paulo: Cortez, 2002.

PIMENTA, S.G.; ALMEIDA, M.I. (Org.). Pedagogia universitária: caminhos para a formação de professores. São Paulo: Cortez, 2011.

TARDIF, M. Saberes docentes e formação profissional. 12. ed. Petrópolis, RJ: Vozes, 2011.

VEIGA, Ilma Passos. Docência universitária na educação superior. In: RISTOFF, Dilvo; SEVEGNANI, Palmira (Org.). Docência na educação superior. Brasília: Instituto Nacional de Pesquisas Educacionais Anísio Teixeira, 2006.

UNIVERSIDADE FEDERAL DO PAMPA. Plano de Desenvolvimento Institucional PDI (2014-2018). Bagé: Unipampa, 2013.

ZABALZA, M.A. O ensino universitário: seu cenário e seus protagonistas. Porto Alegre: Artmed, 2004 